\title{
Elaborando uma análise ator-rede sobre o Role Playing Game "energizando"
}

\author{
Developing an actor-network analysis on the Role Playing Game \\ "energizing"
}

\author{
Raquel Gonçalves de Sousa (kelprofbio@gmail.com) \\ (Mestrado Profissional Educação e Docência da Faculdade de Educação da Universidade Federal de \\ Minas Gerais - PROMESTRE/FAE/UFMG)
}

Fábio Augusto Rodrigues e Silva (fabogusto@gmail.com)

(Mestrado Profissional Educação e Docência da Faculdade de Educação da Universidade Federal de Minas Gerais - PROMESTRE/FAE/UFMG) (Universidade Federal de Ouro Preto)

Resumo: O artigo apresenta um estudo sobre os elementos humanos e não humanos, que foram arregimentados durante a criação do roteiro para o Role Playing Game "Energizando". O referencial teórico-metodológico principal da pesquisa foi a Teoria Ator-Rede, que nos permitiu investigar, no texto desenvolvido para o jogo pedagógico, seu potencial para mobilizar processos de ensino e aprendizagem sobre energia e suas transformações. A análise textual foi realizada com o suporte do software Iramuteq por meio da geração de árvores de similitude, que propiciaram o rastreamento de interações entre os diferentes elementos mobilizados na narrativa. Elas confirmaram que o conceito de energia esteve presente na rede sociotécnica tecida no texto como um processo de equilibração e indicaram que o jogo pode ser um recurso didático importante para a aprendizagem de um dos temas mais importantes para o ensino de Ciências.

Palavras-chave: Energia; Jogo pedagógico; análise textual.

Abstract: The article presents a study about the human elements and not humans who were regimented during the creation of the script for the Role Playing Game "Energizing". The main theoretical-methodological referential of the research was the Actor-Network which allowed us to investigate in the text developed for the pedagogical game its potential to mobilize teaching and learning processes about energy and its transformations. The textual analysis was made with the support of the software Imurateq through the generation of similarity trees that provided the tracking of interactions among the different elements mobilized in the narrative. It confirms that the concept of energy was present in the sociotechnical network woven in the text as an equilibratory process and indicated the game can be an important didactic resource for learning one of most important themes for Science teaching.

Palavras-chave traduzidas: Energy; Pedagogical game; textual analysis.

\section{INTRODUÇÃ̃}


A Teoria Ator-Rede (TAR) foi desenvolvida por Latour (2012) e colaboradores com o propósito de se estudarem a modernidade e os modernos por meio de uma sociologia diferenciada, a sociologia das associações. Os pressupostos teóricos e metodológicos dessa teoria têm nos permitido empreender estudos sobre as práticas sociomateriais, que acontecem nas aulas, as quais mobilizam os conhecimentos científicos e tecnológicos, seja na educação básica ou superior (COUTINHO; VIANA, 2019).

Conforme a abordagem TAR, o conhecimento pode ser compreendido no resultado da interação de vários elementos, que se associam e formam redes. Por exemplo, a ciência e os cientistas precisam rotineiramente justapor elementos sociais, técnicos, conceituais e textuais convertendo-os - traduzindo-os - em fatos científicos. Ao analisar a construção dos fatos científicos, podemos observar um enorme esforço para a manutenção de várias entidades e sujeitos atuando conjuntamente (LAW, 1992; OLIVEIRA, 2019). Para estudar a produção dos fatos científicos, Latour e Woolgar (1997) salientam que os nossos olhares devem abranger humanos e não humanos posteriormente denominados de actantes (LATOUR, 2000) -, que se relacionam nas redes sociotécnicas e, assim, constituem o coletivo e possibilitam as mais diferentes ações (LATOUR, 2012).

Uma rede é formada pelas translações ${ }^{1}$ entre actantes, que podem gerar associações rastreáveis (LATOUR, 2012). A depender da ação de um actante, este se caracterizará nas análises como "intermediário" ou "mediador". Para que o actante seja considerado um mediador, a sua ação precisa ter gerado transformação, distorção e/ou modificação de significados. Caso isso não aconteça e ele atue apenas como um transportador que não gera interferências, o actante é considerado como um “intermediário” da rede (LATOUR, 2012) ${ }^{2}$.

Para os estudiosos da TAR, a noção de rede é fundamental para a compreensão dos fenômenos sociotécnicos; no caso de nosso estudo, para a análise do potencial de mobilização e arregimentação de actantes presentes no roteiro elaborado para o jogo

${ }^{1}$ Translações podem ser identificadas como o trabalho que propicia a interação entre os actantes (LATOUR, 2000).

${ }^{2} \mathrm{Na}$ TAR, a palavra "mediador" não é utilizada no sentido vigotskiano, ou seja, como um elemento necessário para a aquisição de funções superiores no processo de aprendizagem. A discussão de Latour não enfatiza apenas o sujeito, mas sim a rede sociotécnica (COUTINHO et al., 2014). 
Edição Especial: I SSAPEC - Simpósio Sul-Americano de Pesquisa em Ensino de Ciências ISSN: 2595- $4520 \quad$ Vol. 4, n. 3. 2021

pedagógico "Energizando" desenvolvido em uma pesquisa de mestrado no Programa de Mestrado Profissional Educação e Docência da Universidade Federal de Minas Gerais (PROMESTRE/UFMG).

O tema energia foi escolhido para o jogo durante a elaboração do projeto para a seleção do mestrado. Essa escolha teve por base as vivências da primeira autora em relação às dificuldades dos seus estudantes e, também, do desejo por estudar mais sobre essa temática, para um aprimoramento em sua formação como docente que necessita lecionar conhecimentos físicos. Além disso, foi considerado que a escolha do tema para o desenvolvimento do jogo recaiu sobre um assunto com caráter interdisciplinar e bem presente no cotidiano.

Os estudos sobre "formação de conceitos" foram mediadores importantes nesse agregado teórico inicial (FERRARI; CHI, 1998; SILVA, 2000). Eles nos permitem compreender fenômenos naturais - tais como a difusão ou ainda a evolução dos seres, a energia e suas transformações - como processos de equilibração. Ao assumir essa perspectiva ontológica, podemos considerar que a "energia" se encontra na natureza como parte de um sistema caracterizada como a) fenômenos uniformes, simultâneos e contínuos, b) algo que não tem meta específica ou estado final por envolver interações contínuas, c) as quais proporcionam a emergência de propriedades alternativas e ao acaso. Orientados por essa ontologia de equilibração, procuramos pensar em modelos de jogos, que favorecessem uma compreensão da energia a partir das características citadas.

O tipo de jogo escolhido foi o Role-Playing Game (RPG). Essa escolha se justifica pela sua natureza narrativa, o que poderia fomentar o contato do educando com novos conhecimentos. Esperamos, também, maior comunicação entre os(as) alunos(as) bem como a promoção de raciocínio em rede por meio de narrativas conduzidas por objetivos que não se reduzem a apenas uma competição, mas que propiciem vivenciar uma fantasia ou uma jornada (COELHO, 2017). Segundo Cleophas, Cavalcanti e Soares (2018), em situações educacionais, um RPG pode ser considerado um "jogo educativo do tipo pedagógico", já que possui uma intencionalidade pedagógica criteriosamente delineada, mas pode propiciar um maior grau de inovação e não exigir uma preparação anterior acerca dos conhecimentos mobilizados pelo jogo. Ou seja, ao jogar um RPG educativo, alunos poderiam aprender sem a intervenção tão presente ou dirigida por um professor. 
Para a escrita do jogo, fez-se necessária a realização de um trabalho de mobilização em busca de aliados (LATOUR, 2012) mediante o acesso a conhecimentos e saberes presentes em livros, jogos virtuais, sites, pares do mestrado, conhecimentos vivenciais etc. Em princípio, partimos de nossa convicção de que não desenvolveríamos jogos de perguntas ou respostas, ou de trilhas, pois esses formatos não parecem engajar os jogadores para situações, que contemplariam as características de um processo de equilibração (FERRARI; CHI, 1998), algo desejado para a aprendizagem sobre energia e suas transformações. Precisávamos de uma estrutura de jogo, que favorecesse situações com certo grau de abertura, com continuidade, e que propiciasse eventos inesperados e ao acaso.

A escolha de desenvolver um RPG se justificou pelo seu formato narrativo, que, em tese, possibilitaria a imersão em uma história com mais graus de liberdade dos participantes em empreender ações ou situações de acordo com as suas escolhas (COELHO, 2017). Acreditávamos que uma história teria o potencial para mobilizar personagens, artefatos e fenômenos em ambientes, performando ${ }^{3}$ narrativas que conduziriam os alunos a diferentes oportunidades de aprendizagem, as quais constituíssem redes heterogêneas com elementos advindos de nossos estudos sobre o ensino de energia provenientes de aportes da abordagem Ciência, Tecnologia e Sociedade (COUTINHO et al., 2014), da História das Ciências (ORNELLAS, 2006) e da Interculturalidade (CREPALDI, 2012).

Neste artigo, apresentamos uma análise com o objetivo de descrever as associações entre os diferentes actantes, que foram arregimentados na construção do roteiro do jogo pedagógico "Energizando". Por meio deste estudo, avaliamos o potencial desse recurso sociomaterial de ensino para a criação de oportunidades de aprendizagem, que articulem e afetem os sujeitos de forma diferenciada ao mundo.

\section{METODOLOGIA}

No desenvolvimento do jogo, criamos um roteiro, que deve propiciar aos jogadores percorrerem dimensões territoriais familiares, tais como a escola, o parque de

\footnotetext{
${ }^{3} \mathrm{O}$ conceito de performance se relaciona ao resultado de uma assembleia sociomaterial e nos habilita a compreender as ações entre os actantes e de seus coletivos (SØRENSEN, 2010).
} 
diversões e a siderúrgica da cidade, o que se justifica pela intenção de aproximar os assuntos abordados das vivências dos educandos. São ambientes que destacam o tema energia em uma atividade, na qual são mobilizados saberes populares, cotidianos, tecnocientíficos e históricos necessários para a compreensão do tema de maneira mais ampla (CREPALDI; AGUIAR JUNIOR, 2013).

Os jogadores são identificados como seres de uma dimensão paralela, os fotoexploradores que chegaram à Terra por meio de seus veículos denominados "Fotomóveis", que são ondas eletromagnéticas. Cada equipe tem a missão de compreender a relação entre energia e matéria no planeta. Para isso, contam com o auxílio de seus dispositivos eletromagnéticos capazes de os transformar: eles podem assumir a forma humana ou diminuir ao tamanho de um átomo. Os dispositivos, também, auxiliam na comunicação da equipe e com a inteligência artificial responsável por enviá-los na missão. Durante os acontecimentos da história do RPG, os fotoexploradores dialogam com pessoas em seus trabalhos, tais como: a bibliotecária, o maquinista, o palhaço, a diretora, o professor e o zelador. Eles, também, se comunicam com animais e seres diferentes, como o mister fuligem e o boneco de sucata. À medida que cumprem as etapas, os fotoexploradores recebem moedas energéticas, que funcionarão como combustível para levá-los de volta às suas dimensões ao final da missão.

O jogo "Energizando" é composto por um tabuleiro com imagens em preto e branco, cartas coloridas do território e um dado. O tabuleiro é formado por imagens cinzas de quatro territórios de uma cidade: a universidade (Figura 1), a escola, o parque de diversões e a siderúrgica. Esses territórios são divididos em 12 seções com linhas e números, nas quais são depositadas cartas, que são réplicas coloridas dos quadrantes, os quais formam os territórios. 


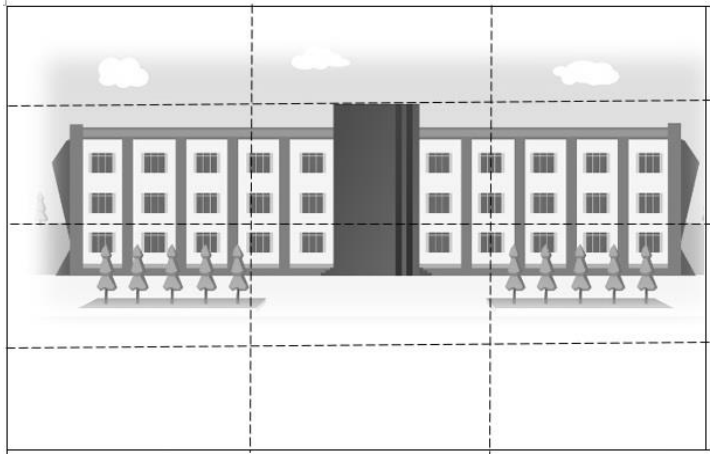

Figura 1 - Ilustração do Território Universidade.

Fonte: os autores.

No total, são 48 cartas numeradas, que indicam o número da página do livro de cartas, no qual está a narrativa com informações sobre energia, processos de transferência de energia ou aplicações tecnológicas. Em alguns momentos, as instruções do jogo orientam os jogadores, que utilizem o dado com o intuito de dinamizar e trazer aleatoriedade para as partidas.

Os jogadores devem ser divididos em quatro equipes, que participam de forma independente. No primeiro momento, é essencial a escolha de um mestre da equipe para realizar a leitura das cartas. Eles começarão pela carta de menor valor. Entretanto, dependendo da escolha realizada pelos alunos, a próxima carta, não necessariamente, seguirá a ordem numérica. O jogo foi elaborado com mais percursos com a intenção de torná-lo intrigante ao colocar na equipe o poder de decisão e, portanto, suas consequências. À medida que a equipe lê as cartas, avança nos territórios ao colocá-las por cima do tabuleiro. Nesse sentido, o ranque de ganhadores vai se formando do primeiro grupo que conseguir completar o território até o último a cumprir esse feito. Ao longo do jogo, dependendo da escolha feita pela equipe, a carta irá indicar a mudança de território para outra equipe, que iniciará ou continuará o jogo. Um integrante de cada equipe registra a numeração percorrida por eles durante a jornada. A última carta a ser utilizada por todas as equipes será a do painel fotovoltaico conduzindo eletricidade até a lâmpada das ideias.

Portanto, o RPG "Energizando" traz elementos que se aproximam e outros que se diferem dos RPG tradicionais. Algumas das aproximações se referem à proposição de uma história narrada com suas ambientações, à escolha de um mestre por grupo e, também, à proposição de caminhos diversos para o desenrolar da história. Entretanto, 
diferencia-se ao elaborar caminhos diversos, porém preestabelecidos. É importante destacar que o Currículo Referência de Minas Gerais ${ }^{4}$ foi acessado como uma orientação durante a elaboração da narrativa do jogo.

A nossa análise dos actantes mobilizados no texto criado para o RPG foi realizada por meio do software Iramuteq. Esse programa propiciou um exame mais consistente e mais abrangente do texto que constitui a história do RPG. Dentre o rol de possibilidades oferecidas pelo programa, decidiu-se pela "análise de similitude", pois favorece representar as associações presentes em uma rede heterogênea de humanos e não humanos, que são mobilizados no texto do jogo "Energizando".

O objetivo dessa análise de similitude “[...] é estudar a proximidade e as relações entre os elementos de um todo, na forma de árvores máximas: o número de ligação entre dois itens em evolução" (MARCHAND; RATINUAD, 2012, p. 688). A geração dessas árvores permite observações sobre a conexidade entre as palavras, o que propicia ao analista uma estrutura ramificada de termos.

Para tanto, os textos das cartas foram tratados para gerar um corpus textual adequado ao software. Esse tratamento envolveu a inserção de linhas de comando antes de cada carta além da retirada ou modificação de alguns caracteres e palavras. Outro aspecto importante foi o critério de considerar apenas as palavras que se repetissem mais de cinco vezes, delimitação feita com o intuito de melhorar a visualização final da árvore

As árvores de similitude geraram diagramas, que se constituíram em instrumentos para que pudéssemos seguir os actantes, identificando-os e constatando as suas interações como esperado em uma análise estudo ator-rede. Esses diagramas nos ofereceram subsídios para nos dedicarmos ao trabalho de descrição das redes sociotécnicas informando sobre "quem", "o que" e "como atua" por meio de um texto narrativo (LATOUR, 2012); um texto que nos propicia produzir teorias sobre a realidade e o conhecimento em um estudo sobre um material pedagógico e poderá contribuir para futuros processos de aprendizagem (SØRENSEN, 2010).

\footnotetext{
${ }^{4}$ As diretrizes e normativas da Base Nacional Comum Curricular foram incorporadas ao Currículo Referência de Minas Gerais. Esses documentos apresentam, portanto, um papel complementar, pois a BNCC é uma referência nacional com vista à promoção da educação, e o currículo organiza as diretrizes quanto ao que ensinar, o por que ensinar e o quando, incluindo, assim, algumas especificidades das questões regionais do estado de Minas Gerais (MINAS GERAIS, 2018).
} 


\section{RESULTADOS E DISCUSSÕES}

A nossa análise começou pelo texto do roteiro desenvolvido para o território da universidade. Neste, destaca-se um pouco da história do pensamento científico, em relação ao conceito de energia, principalmente quando os fotoexploradores passam pela biblioteca. No pátio da universidade, há uma fonte. Ao se observarem a umidade do ar e o termômetro ao lado da fonte, discute-se a relação entre energia e as transformações dos estados físicos da matéria, demonstrando, ainda, a diferença entre os conceitos de temperatura e calor. Outra inserção da história da ciência se dá, também, por meio de uma conversa com Gabriel Fahrenheit. As transformações energéticas, ainda, são abordadas no roteiro quando se narra um evento de uma aula prática com arco e flecha. Os conhecimentos relativos às fontes de "geração" de energia elétrica são abordados durante uma palestra no auditório. A árvore de similitude do território universidade é apresentada na Figura 2.

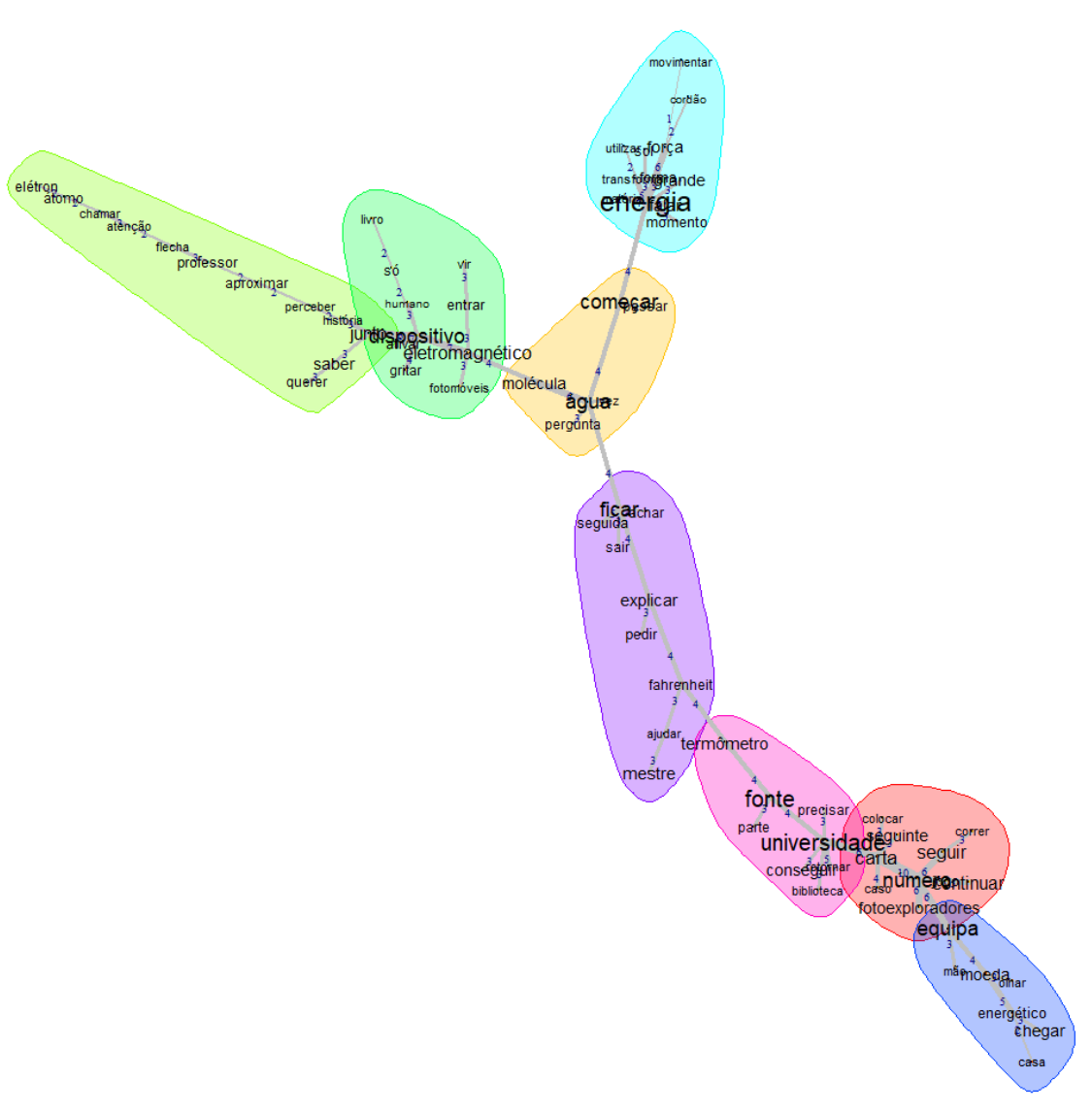


Edição Especial: I SSAPEC - Simpósio Sul-Americano de Pesquisa em Ensino de Ciências

Figura 2 - Árvore máxima de similitude do corpus textual da universidade com configurações.

Fonte: análise do corpus textual utilizando o software Iramuteq.

A princípio, é possível perceber a centralidade dos actantes energia, água, fonte, dispositivo eletromagnético, ficar, universidade, começar e número. Esses actantes centrais podem ser identificados como aqueles com potencial para serem considerados mediadores, ou seja, entidades capazes de deixar rastros, dar sentido à ação e gerar a diferença ou algo novo (LATOUR, 2012). O nicho da palavra "energia" demonstra uma ligação desta com verbos que denotam movimento e mudança (movimentar, transformar e utilizar), confirmando a presença da ideia de energia vinculada a processos contínuos, algo desejado para uma compreensão do conceito em uma ontologia de equilibração (FERRARI; CHI, 1998).

No roteiro da escola, o conceito de energia aparece vinculado ao processo de fotossíntese e respiração, com ênfase na energia química das ligações entre os átomos e, também, nas transformações energéticas. Destaca-se a abordagem dos aspectos relativos à energia elétrica, tais como: materiais isolantes e condutores, circuitos elétricos, funcionamento de aparelhos elétricos da escola, economia de energia e risco de choque elétrico. Nessa jornada pela escola, os fotoexploradores passam, dentre outros lugares, por dentro de plantas e do corpo humano; nas dimensões humanas, presenciam aulas práticas, trocas de lâmpadas e reunião de pais, e conseguem até conversar com um ventilador.

A árvore de similitude do território escola apresenta um eixo central, que conecta a história passando pelos actantes: energia - energético - dispositivo eletromagnético agora - número - escola (Figura 3). 


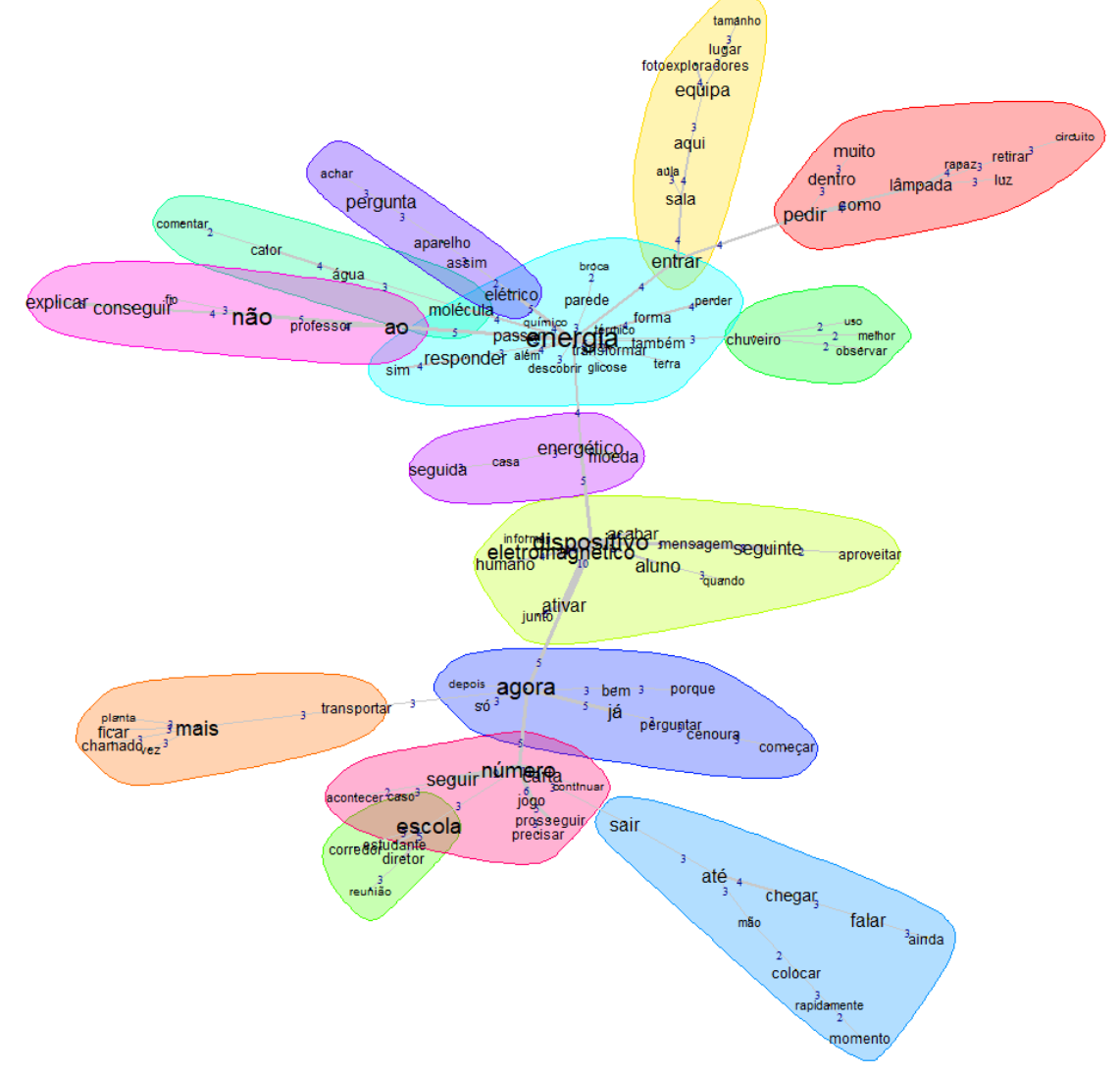

Figura 3 - Árvore máxima de similitude do corpus textual da escola com configurações.

Fonte: análise do corpus textual utilizando o software Iramuteq.

Observa-se, em sua especificidade, que a palavra "energia", apesar de novamente aparecer ligada a alguns verbos, apresenta nesse território uma relação maior com a matéria por meio da ligação forte com palavras como "químico", "molécula", "térmico", "glicose", "parede" e "chuveiro". Essas associações se relacionam à arregimentação de elementos, que, comumente, são utilizados para se trabalhar o conceito de energia de modo mais escolarizado com ênfase em situações e exemplos canônicos das aulas de Ciências (CREPALDI; AGUIAR JUNIOR, 2013).

Entre os conhecimentos mobilizados por meio do território "parque de diversões", destacam-se: as transformações de energia potencial gravitacional em energia cinética, $o$ atrito e a transformação de energia mecânica em térmica, os diferentes mecanismos de controle de temperatura apresentados pelos seres vivos, a relação entre energia química e cadeia alimentar, a quantificação da energia potencial, a interação entre calor e a 
Edição Especial: I SSAPEC - Simpósio Sul-Americano de Pesquisa em Ensino de Ciências

modificação estrutural da matéria, o desperdício de energia com iluminação pública inadequada e o funcionamento de um gerador elétrico.

O eixo central da história do "parque de diversões" se estruturou em torno dos seguintes actantes: número - energia - brinquedo - parque - humano - dispositivo (Figura 4).
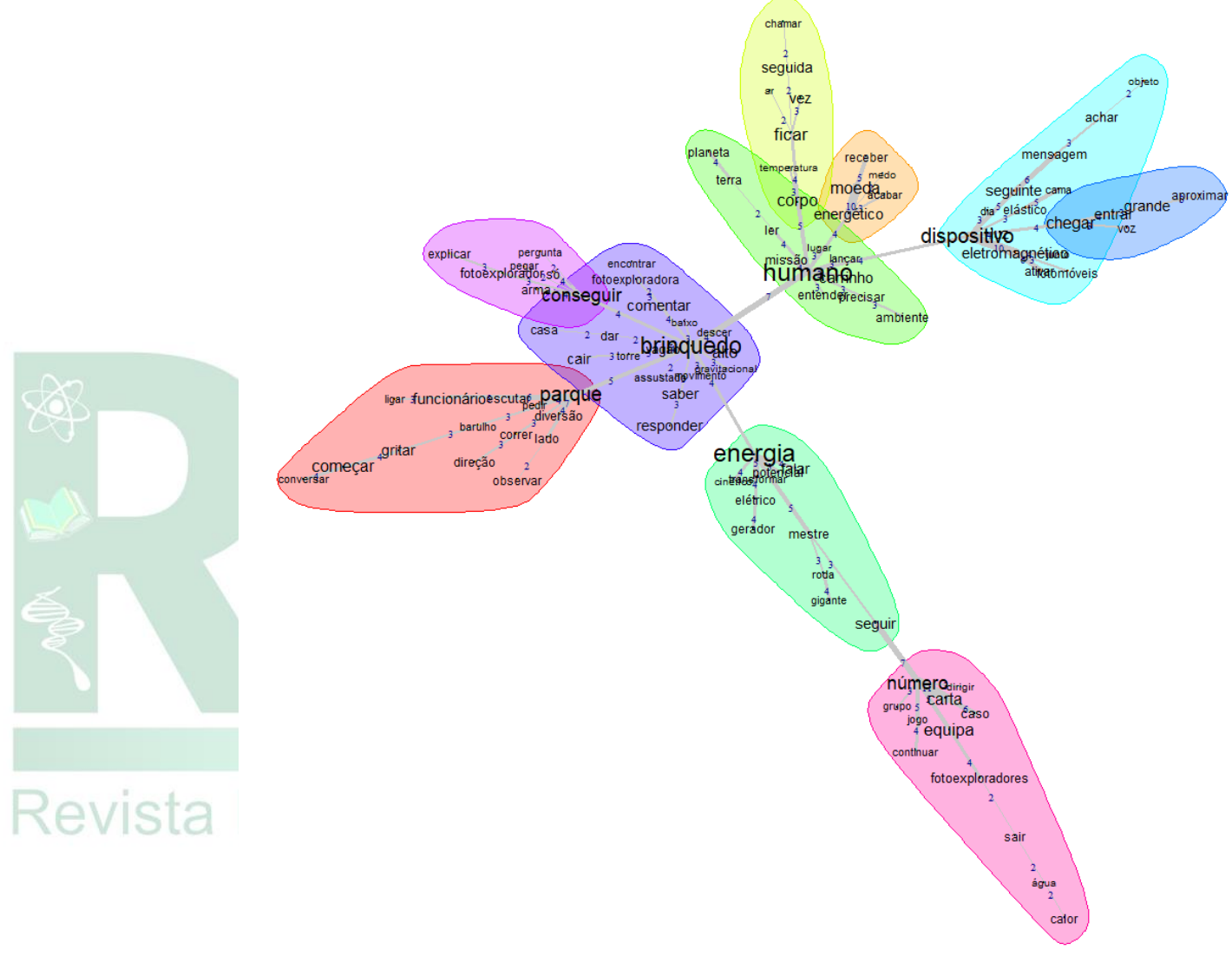

Figura 4 - Árvore máxima de similitude do corpus textual do parque de diversões com configurações.

Fonte: análise do corpus textual utilizando o software Iramuteq.

Há uma possível explicação para o fato de a palavra "brinquedo" estar ligada à palavra "gravitacional” e, em seguida, às palavras "energia" e "potencial”. Isso decorre do aproveitamento da altura de determinados brinquedos para inclusão da discussão sobre energia potencial gravitacional. Outro aspecto que chama a atenção nessa árvore de similitude é a presença, em quase todos os nichos, de uma quantidade maior de verbos em comparação, por exemplo, com o território escola, demonstrando o alcance 
de um maior dinamismo nesse roteiro, com mais momentos de ações imagéticas, tais como: chegar, aproximar, achar, chamar, lançar, cair, correr e gritar. Desse modo, identificamos um território com um bom potencial para favorecer uma imersão mais contextualizada sobre energia por meio da criação de oportunidades de aprendizagem, que extrapolam uma visão limitada dos conceitos e processos mobilizada em aulas e livros de Ciências (CAVALCANTI, 2018).

$\mathrm{Na}$ aventura proposta para o território siderúrgica, os fotoexploradores seguem em vagões de um trem, em que se encontram com um maquinista negro, que conversa um pouco sobre a importância dos conhecimentos técnicos trazidos por seus ancestrais no processo de exploração do ouro. O personagem, também, introduz o assunto sobre a diferença entre as máquinas a vapor e as locomotivas modernas. No encontro dos fotoexploradores com os inventores Thomas Savery, Thomas Newcomen, James Watson e Richard Thevithck, os conhecimentos relativos à evolução das máquinas a vapor e dos motores se fazem presentes, mobilizando, também, os aspectos sobre "conversão contínua de calor em trabalho" e "ciclos entre fontes quentes e frias". O trem chega a uma siderúrgica na companhia de moléculas de oxigênio e do mineral chamado hematita. Os jogadores têm a oportunidade de, ao passarem para dimensões atômicas, ativando seus dispositivos eletromagnéticos, vivenciarem imageticamente todo o processo de fundição do minério. Em síntese, a história desse território oportuniza a realização de ligações entre energia, conhecimentos da mineração e processos de siderurgia.

$\mathrm{O}$ eixo com os actantes centrais do roteiro da siderúrgica é composto pelas palavras: água - ferro - ficar - oxigênio - energia - carta - número - continuar - equipa - missão - fotoexplorador - dizer - humano - fotoexploradores - dispositivo (Figura 5). 


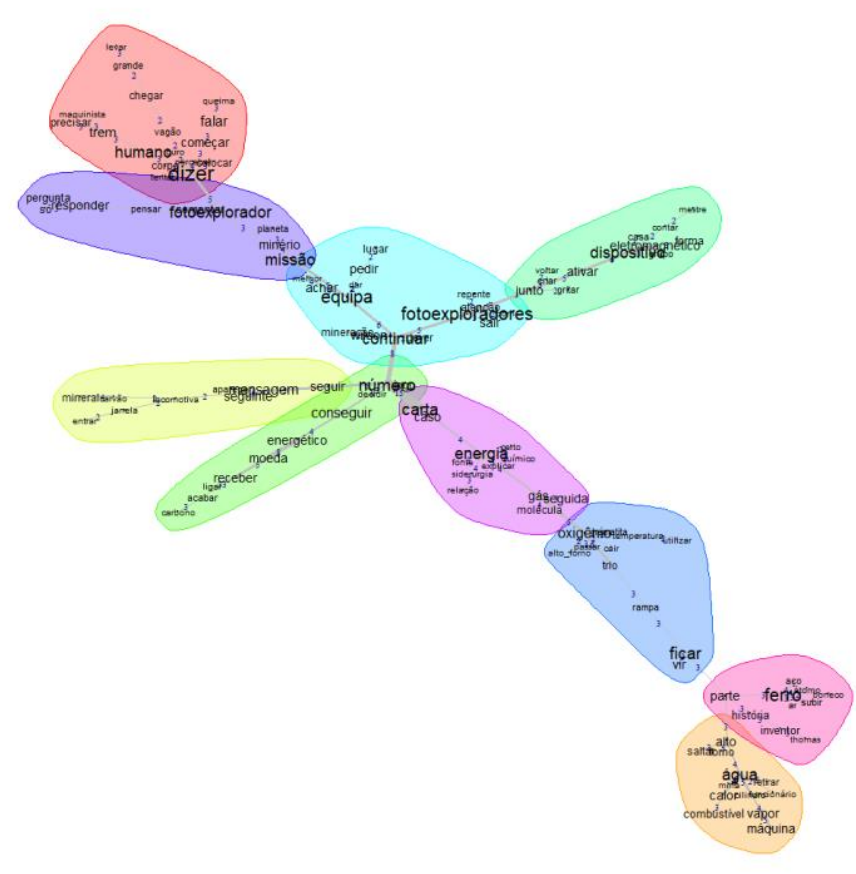

Figura 5 - Árvore máxima de similitude do corpus textual da siderúrgica com configurações.

Fonte: análise do corpus textual utilizando o software Iramuteq.

No território siderúrgica, foi necessário um acesso maior a conhecimentos químicos para a criação dessa parte da história, o que fica demonstrado tanto no nicho de cor lilás, com a palavra "energia” ligada a termos como gás, molécula e químico, quanto no nicho azul, com a palavra "oxigênio" ligada à "temperatura", "hematita" e "alto-forno"; consequência da vinculação, nessa etapa da história, dos conceitos de energia às reações químicas que acontecem dentro de um alto-forno. A palavra "ferro" se conecta com "aço" e "boneco", no nicho rosa, em decorrência da parte da história em que um boneco de sucata, usando o exemplo da composição do seu próprio corpo, aparece para dialogar sobre a diferença entre o ferro e o aço, trazendo à tona, também, a possibilidade de práticas sustentáveis para a diminuição da extração de minérios.

Os mediadores mobilizados nos possibilitam aventar que, nesse território, abrese uma oportunidade de aprendizagem de aspectos tecnológicos sem uma dissociação de questões sociais e históricas (SANTOS; MORTIMER, 2002), como a Revolução Industrial, a escravidão e a sustentabilidade. 
Em síntese, parece que, ao produzir esse roteiro, os actantes, que foram mobilizados e dispostos na rede sociotécnica heterogênea do RPG, podem criar oportunidades de uma aprendizagem diferenciada (LATOUR, 2004), compreendendo energia e suas transformações, de forma lúdica e mais articulada, a um mundo altamente tecno-sociocientífico (LATOUR, 2000). Ao buscar uma imersão no modo lúdico (LEMOS, 2015), por meio do RPG Energizando, constituímos um recurso e, quem sabe, um mundo, que pode contribuir para performar uma cadeia de significação (GOULART; COUTINHO; PEREIRA, 2019).

\section{CONCLUSÕES}

A escolha pela "análise de similitude" nos permitiu rastrear as associações entre os diversos actantes que compõem a rede sociotécnica da história do jogo Energizando. Uma metodologia, também, condizente com os pressupostos da TAR de não se definir antecipadamente quem e o que está agindo, mas sim de perscrutar em trabalho cuidadoso em busca de identificar e explicar as associações entre os actantes. Temos, portanto, uma avaliação de um recurso educacional híbrido, um coletivo que nos parece ter potencial de mobilizar uma rede heterogênea e dinâmica de actantes em uma prática sociomaterial de ensino e aprendizagem sobre o tema Energia.

Em relação à observação dos actantes centrais e de seus nichos, emergiu a constatação de que o conceito de "energia" esteve presente ao longo da história como um processo de equilibração conforme abordagem ontológica escolhida incialmente. Também, foi possível analisar que, na rede do "parque de diversões", os conceitos foram arregimentados de uma maneira mais integral e dinâmica, demonstrando o potencial desse território, seja imagético ou real, para o ensino dessa temática. As ligações da rede do "território escola" revelaram que, para a criação dessa parte da história, foram acessados exemplos canônicos do ensino de Ciências. Por último, a rede sociotécnica do "território siderúrgica" mobilizou aspectos tecnológicos sem os dissociar de questões socioambientais e históricas.

Em suma, o jogo "Energizando" apresenta potencial para ser um recurso mobilizador de ações para a aprendizagem mais ampla do tema Energia. Seu formato narrativo traz a possibilidade de os estudantes, ao lerem falas de personagens diversos, 
Edição Especial: I SSAPEC - Simpósio Sul-Americano de Pesquisa em Ensino de Ciências

ISSN: 2595- $4520 \quad$ Vol. 4, n. 3. 2021

vivenciarem, pela imaginação, diferentes situações envolvendo energia e suas transformações. Por fim, esperamos que a aplicação futura do jogo em uma situação de ensino em aulas de Ciências possa ajudar a trazer mais subsídios para se entenderem os potenciais e limitações desse material quando em conexão com outros objetos e entidades humanas.

\section{REFERÊNCIAS}

CAVAlCANTI, E. L. D. Role Playing Game e ensino de química. 1. ed. Curitiba: Appris, 2018. $91 \mathrm{p}$.

ClEOPHAS, M. G.; CAVALCANTI, E. L. D.; SOARES, M. H. F. B. Afinal de contas, é Jogo Educativo, Didático ou Pedagógico no Ensino de Química/Ciências? Colocando os Pingos nos “is”. In: CLEOPHAS, M. G.; SOARES, M. H. F. B. Didatização Lúdica no Ensino de Química/Ciências: teorias da aprendizagem e outras interfaces. São Paulo: Editora Livraria da Física, 2018. p. 33-46.

COELHO, I. M. A. O uso de Role Playing Game (RPG) como ferramenta didática no ensino de Ciências. 2017. 128 f. Dissertação (Mestrado) - Universidade Federal de Minas Gerais, Belo Horizonte, 2017.

COUTINHO, F. A.; SILVA, F. A. R.; MATOS, S. A.; SOUZA, D. F.; LISBOA, D. B. Proposta de uma unidade de análise para a materialidade da cognição. Revista SBEnBIo, n. 7, 2014. 13 p. Disponível em:

<https://www.repositorio.ufop.br/bitstream/123456789/8433/1/ARTIGO_PropostaUnid adeAn\%c3\%a1lise.pdf>. Acesso em: 23 jun. 2019.

COUTINHO; F. A; VIANA, G. M. Alguns elementos da teoria Ator-rede. In: COUTINHO; F. A; VIANA, G. M. (Org.). Teoria Ator-rede e educação. 1. ed. Curitiba: Appris, 2019. p. 17-37.

CREPALDI, R. S. Da energia pensada à energia vivida: um diálogo intercultural com as ciências. 2012. 165 f. Dissertação (Mestrado em Educação) - Faculdade de Educação, Universidade Federal de Minas Gerais, Belo Horizonte, 2012. 
Edição Especial: I SSAPEC - Simpósio Sul-Americano de Pesquisa em Ensino de Ciências ISSN: 2595- $4520 \quad$ Vol. 4, n. 3. 2021

CREPALDI, R. S.; AGUIAR JUNIOR, O. G. A formação de conceitos como ascensão do abstrato ao concreto: da energia pensada à energia vivida. Investigações em Ensino de Ciências, v. 18, n. 2, p. 299-325, 2013. Disponível em:

$<$ https://www.if.ufrgs.br/cref/ojs/index.php/ienci/article/view/132>. Acesso em: 19 jun. 2019.

FERRARI, M.; CHI, M. T. H. The nature of Naive explanation of nature selection.

International Journal Science Education, Londres, v. 20, n. 10, p. 1231-1256, 1998.

GOULART, M. I. M.; COUTINHO, F. A.; PEREIRA, A. F. "Quando é que nós vamos dar a resposta certa?" Formas híbridas de categorização na exploração do mundo por crianças pequenas. In: COUTINHO; F. A; VIANA, G. M. (Org.). Teoria Ator-rede e educação. 1. ed. Curitiba: Appris, 2019. p. 67-94.

LATOUR, B. Ciência em ação: como seguir cientistas e engenheiros sociedade afora. São Paulo: Ed. da UNESP, 2000.

LATOUR, B. How to Talk About the Body? The Normative Dimension of Science Studies. Body \& Society, Califórnia: Sage, v. 10, n. 2-3, p. 205-229, 2004.

LATOUR, B. Reagregando o social: uma introdução à teoria do ator-rede. Edufba, 2012.

LATOUR, B.; WOOLGAR, S. A vida de laboratório: a produção dos fatos científicos. Rio de Janeiro: Relume Dumará, 1997.

LAW, J. Notas sobre a teoria do ator-rede: ordenamento, estratégia e heterogeneidade. Tradução Fernando Manso. 1992. Disponível em: <http://www.necso.ufrj.br/Trads/Notas\%20sobre\%20a\%20teoria\%20Ator-Rede.htm>. Acesso em: 24 jul. 2019.

LEMOS, A. Por um modo de existência do lúdico. Revista Contracampo, v. 32, n. 2, p. $4-17,2015$.

MARCHAND, P.; RATINAUD, P. L'analyse de similitude appliquée aux corpus textuels: les primaires socialistes pour l'élection présidentielle française (septembreoctobre 2011). Actes des 11 eme Journées internationales d'Analyse statistique des Données Textuelles. JADT, 2012, p. 687-699, 2012. Disponível em: $<$ http://lexicometrica.univparis3.fr/jadt/jadt2012/Communications/Marchand,\%20Pascal 
Edição Especial: I SSAPEC - Simpósio Sul-Americano de Pesquisa em Ensino de Ciências

ISSN: 2595- $4520 \quad$ Vol. 4, n. 3. 2021

\%20et\%20al.\%20\%20L'analyse\%20de\%20similitude\%20appliquee\%20aux\%20corpus \%20textuels.pdf>. Acesso em: 15 ago. 2020.

MINAS GERAIS. Currículo Referência de Minas Gerais. Secretaria de Estado de Educação de Minas Gerais -SEE/MG, 2018

OLIVEIRA, B. B. Performance da Prática como Componente Curricular na formação de Professores de Ciências e Biologia. 2019. 125. Dissertação (Mestrado) Universidade Federal de São João del-Rei, São João del-Rei, 2019.

ORNELlAS, A. J. A energia dos tempos antigos aos dias atuais. Maceió: EDUFAL, 2006.

SANTOS, W. L. P.; MORTIMER, E. F. Uma análise de pressupostos teóricos da abordagem C-T-S (Ciência - Tecnologia - Sociedade) no contexto da educação brasileira. ENSAIO - Pesquisa em Educação em Ciências, v. 2, n. 2, p. 1-23, 2002.

SILVA, F. A. R. O Darwinismo e os Biólogos: Um estudo sobre a natureza das concepções alternativas sobre evolução. 2000. 78 f. Monografia (Licenciatura em Ciências Biológicas) - Faculdade de Educação, Universidade Federal de Minas Gerais, Belo Horizonte, 2000.

SØRENSEN, E. The materiality of learning. Cambridge: Cambridge University Press, 2010. 